\title{
Innovating Digital Literacy for History Students During COVID-19 and Beyond
}

David Sye, Murray State University

\begin{abstract}
Due to the COVID-19 pandemic, many cultural institutions that house archives and special collections closed their doors or otherwise limited in-person access. For disciplines that utilize special collections for research, such as history, students faced challenges as they worked to conduct original primary source research for projects, theses, and dissertations. At Murray State University, I provided library instruction that focused on accessing digital archives and collections. Concepts such as "digital archival literacy" are not only important to discuss now, but have implications beyond the pandemic as research is increasingly performed in a digital environment.

\section{KEYWORDS}

COVID-19 pandemic, digital collections, digital literacy, digital archival literacy
\end{abstract}

\section{SUGGESTED CITATION}

Sye, D. (2022). Innovating digital literacy for history students during COVID-19 and beyond. Journal of New Librarianship, 7(1), 11-16. https://doi.org/10.33011/newlibs/11/2

This is an Open Access article distributed under the terms of the Creative Commons Attribution 4.0 International License (http://creativecommons.org/licenses/by/4.0), which permits unrestricted use, distribution, and reproduction in any medium, provided the original work is properly cited. 
The COVID-19 pandemic has caused many businesses and organizations to close to the public, including historical and cultural institutions that maintain archives and special collections. Even the National Archives and Records Administration (NARA) closed all research rooms nationwide and was in full effect until June 2021 (Ferriero, 2021). Limited access to such collections poses a challenge to historians and researchers, particularly students conducting original research towards a thesis, dissertation, or similar graduation requirement. At Murray State University, for example, second-year graduate students in the history program are required to write a research article based on original primary source material as part of their graduation requirements. Due the limits placed on in-person archival access since March 2020, it was difficult for students to access needed archival material. History faculty reached out to me, their subject librarian, to try to find a solution for their students.

An initial solution to this problem was relatively easy to arrive at. During the fall, and moving forward, students would have to use digital archives for large parts of their research. The challenge, however, is that when history students are trained in archival use, the focus is usually on using physical collections. For example, the Information Literacy Guidelines and Competencies for Undergraduate History Students include that students should be able to use "finding aids to identify material in archival or manuscript collections" (Instruction and Research Services Committee, History Section, 2013, 2.3.3). When Weiner et al. (2015) drafted archival literacy competencies and surveyed faculty, archivists, and librarians, some of the feedback indicated that the list only focused on print resources and physical archives (pp. 162163). This focus on how to use physical archives is logical, as most people do not have experience using an archival collection until they conduct research themselves. History faculty, archivists, and librarians, however, should not take this for granted and assume that archival literacy competencies developed for using physical collections are automatically applicable for digital archives and repositories. In order to properly prepare students for research in the internet age and the COVID-19 era, we must place digital literacy concepts and archival research strategies in the same context.

Digital literacy refers to using "information and communication technologies to find, understand, evaluate, create, and communicate digital information" (Office for Information Technology Policy's Digital Literacy Task Force, 2013, p. 2). The key idea here is the use of technologies. This can refer to things such as search engines, online public access catalogs, social media platforms, and document/media viewing tools. In the current information environment, sources can be accessed through many different tools. Students may or may not receive specific instruction on certain tools needed for their work. For many of the instruction sessions I deliver or modules I create, I incorporate digital literacy in giving tutorials on EBSCO databases, some of our digital newspaper repositories, or any other tool necessary for their work. 
Weiner et al.'s (2015) archival literacy competencies for history students are divided into seven areas: accurately conceive of primary sources; locate primary sources; use a research question, evidence, and argumentation to advance a thesis; obtain guidance from archivists; demonstrate acculturation to archives; follow publication protocols; and related advanced skills (pp. 165-168). A key area that is taught to students is how to locate primary sources. Key competencies in locating primary sources include identifying different types of repositories that collect primary sources and what types of materials they may have, reviewing finding aids and archival policies, locating nearby repositories, and understanding the lack of online access to many archival materials (Weiner et al., 2015, p. 165). These main ideas were incorporated into the instruction session for history graduate students.

As previously mentioned, graduate history students at Murray State University write a research article as part of their capstone class. At the beginning of the Fall 2020 semester, I was contacted by the history faculty member who teaches the capstone. They identified a need for instruction regarding using digital primary sources that the library subscribes to, as well as finding and assessing other digital collections. I therefore planned this session with two categories in mind: using tools/resources and locating primary sources.

The first component, providing instruction on our various collections, was both straightforward and a common request for information literacy sessions. The library subscribes to a variety of archived newspaper collections, some of which are hosted by the same database provider. It is important for students be familiar with the search and viewing interface, so a brief tutorial on these databases via GALE and ProQuest was included. Chronicling America was also shared, and we also discussed how the existence of grants and state newspaper repositories affected the availability of various sources. In addition to newspaper databases and collections, brief tutorials on the Internet Archive and HathiTrust were included in the session, with best practices on how to use them.

At the graduate level, students commonly have to conduct original research on a highly specific topic. This typically involves analyzing unique sources, so collections on popular topics found using basic keywords on Google would most likely not contain materials to facilitate such research. Before explaining how to look for collections, it was important to explain what to look for. Because many digital collections contain materials from special collections that have been digitized by the owning institution, it was prudent to discuss what institutions have archives/special collections. Common institutions include college/university libraries, public libraries, museums, historical societies, and government agencies. It was also worth mentioning that professional organizations, religious organizations/institutions, hospitals/health systems, and businesses/corporations may also have archives, albeit with mostly collections related to their purpose. 
Even when you know what to look for, searching for digital collections online is still a daunting task. In order to identify potential collections to use and what websites to check, I suggested students ask the following questions:

- What geographic locations are connected to my research?

- What organizations are connected to my research?

- What key people are connected to my research (and where are they from)?

Students can use the answers to these questions to identify institutions that house collections. For example, the Joseph R. Biden, Jr. Senatorial Papers collection is currently being processed and will be made accessible by the University of Delaware, as opposed to someplace in Washington D.C., which was donated to the library in 2012 due to Biden's ties to the state and university (University of Delaware Library, Museums and Press, n.d).

Other advice given included asking the institution if any materials related to their topic could be archived or managed elsewhere. Most digital collections and repositories are hosted on the institution's website, which should also include contact information. When one comes across a special collection or repository, it is not always clear right away if it will be useful. I advised students to take a main term or facet of their research question and type it in the search interface, with the idea that the term would be included in metadata for relevant materials, a collection guide, or in full-text if Optimal Character Recognition (OCR) is enabled on documents. Also, it was important for them to check to see if the collection included the types of material they were looking for, in addition to covering the appropriate date range. Many of these strategies align with various competencies of archival literacy.

\section{Digital Archival Literacy}

After I gave the instruction session, I reflected on how to better prepare students for using digital archives and repositories. Jensen (2020) explores the idea of "digital archival literacy," which provides a framework for the everyday use of digital archives and factors that shape online content and its availability (p. 251). Four components of digital archival literacy can be extracted from Jensen: availability of sources, bias in representation, aspects of the search system, and responsible usership. Having such a framework is crucial right now, as the use of digital archives surges due to a large shift to online instruction and limited access to physical archives. These components allow librarians and instructors to focus on core aspects of the online research experience pertaining to archives. In return, students will be able to think critically about the nature of digital archives and its research environment.

\section{Availability of Sources}

In a physical archive, most materials are cataloged and registered in the same way, such as listed in a detailed inventory or finding aid. They also have a designated location within the repository where they can be found and accessed. In a digital archive, however, materials are 
selected and prioritized for the digitization process to be made available online. This means that a certain source may physically exist, but is not accessible to someone researching online. People outside the humanities or libraries field may think that digitization consists of simply scanning materials and uploading them to the internet, thus institutions should just "scan everything." Unfortunately, there are numerous costs and labor associated with digitization, and digitization projects typically rely on additional or external funding (Jensen, 2020, p. 254). What ends up happening is institutions with a smaller budget will have less materials available digitally. Students need to acknowledge how the availability of digitized sources is impacted by layers of privilege, and understand how materials end up accessible via the internet.

\section{Bias in Representation}

The availability of sources online can be biased. We live in a world where clicks and downloads matter, which in an archival context means that popularity and usage statistics typically drive digitization priority. For example, NARA's (2014) digitization strategy explains that digitization projects will be prioritized according to criteria based on significance and use. With many institutions digitizing materials that are already popular, minor or otherwise unresearched collections will not be made available digitally. This will widen the gap of digitized material available between different subject areas or topics. More sources available on a topic will lead to more research on it, which will create more sources on the topic and draw even more attention to it. This bias in availability can have a compounding effect that results in certain materials never meeting digitization criteria due to lack of popularity. Amidst this issue, it is important to figure out what is omitted or missing online. For physical collections, this type of information would most likely be included in a finding aid or other supporting documentation. This may not be the case for digital collections, and certainly not for open-access repositories such as the Internet Archive or HathiTrust. When working with students preparing to conduct research online, students should reflect on this idea of representation and ask, "What can I expect to find?" They could write a reflective essay or create a list documenting the types of sources that are available digitally pertaining to their topic.

\section{Aspects of the Search System}

By design, most digital repositories should have some sort of search system in place. Students must be able to effectively use a search interface to find material. While search systems may differ from each other, there are three types of components that librarians and faculty should explain to students so they can use them for their advantage: predefined subject categories, search fields and sorting of results, and metadata. Many students default to keyword or full-text searches, but encouraging them to look at and utilize these aspects will help them explore digital archives and find relevant materials. When discussing these aspects with students, it is important to emphasize the human processes involved with actually creating the subject categories, determining search fields, and adding metadata to item records. Circling back to bias in representation, the focus on digitizing popular sources may result in a search 
interface that caters to general browsing, rather than research (Jensen, 2020, p. 258). Students, therefore, should consider multiple ways relevant materials may be defined within a search system. Instructors should expose their students to a variety of repositories with different search systems so they can practice finding materials.

\section{Responsible Usership}

Researchers, in particularly those using digital archives, have a responsibility to disclose that they accessed and used digitized sources. When we acknowledge that we use digital sources, we bring attention to the work and labor involved in making materials available digitally. Sukovic (2009, as cited in Blaney \& Siefring, 2017, para. 9), however, found that with regards to humanities research, references often did not accurately represent the use of electronic sources. In fact, approximately "a third of researchers fail to indicate their use of digital resources at all" (Blaney \& Siefring, 2017, para. 29). The lack of acknowledgement makes the use of digital sources invisible and hides the value of digital practice. One simple habit we can teach students is to note that they accessed digitized material in their references (Jensen, 2020, p. 261). Many citation styles specify how to do this, even if there is not a specific citation format for a digital version of an item. For example, the Chicago Manual of Style states, "Authors citing sources consulted online should generally include a uniform resource locator, or URL, as the final element in a citation...” (The University of Chicago Press Editorial Staff, 2017, p. 745). Students should always include a DOI or URL when citing such digital material and use a permalink if available.

\section{Conclusion}

Even in a post-pandemic environment, digitized primary sources will play a vital role in research. One long-term goal would be to have a dedicated course about the methods and implications of using digital archives, to be taught in collaboration with department faculty. In the meantime, how can librarians help prepare students to find relevant primary sources amidst the information behemoth that is the internet? One option is to incorporate these concepts into library instruction. At Murray State University, for example, this includes live instruction sessions (provided via Zoom at the moment) or learning modules that can be imported to a course's Canvas site (Murray State University's learning management system). Librarians can also work with faculty to embed these concepts into their own instruction, which can look like providing consultation on lesson planning or helping develop assignments that are aimed at reinforcing these skills. One thing to keep in mind is that "digital archival literacy" is not yet a widely used term, as its first documented use was by Jensen at the 2017 Danish DIGHUMLAB Conference (Bødker, 2018). One possibility is that digital archival literacy is addressed under the guise of digital literacy, archival literacy, or good practice. It is important for librarians to work together to discuss strategies for helping our students tackle this challenge. 


\section{References}

Blaney, J., \& Siefring, J. (2017). A culture of non-citation: Assessing the digital impact of British History Online and the Early English Books Online Text Creation Partnership. DHQ: Digital Humanities Quarterly, 11(1). http://www.digitalhumanities.org/dhq/vol/11/1/000282/000282.html

Bødker, H. (2018). Journalism history and digital archives. Digital Journalism, 6(9), 1113-1120. https://doi.org/10.1080/21670811.2018.1516114

Ferriero, D. S. (2021, May 24). An update for researchers from the archivist. National Archives News. https://www.archives.gov/news/message-from-archivist-to-researchers-0.5-24$\underline{2021}$

Instruction and Research Services Committee, History Section. (2013). Information literacy guidelines and competencies for undergraduate history students. Reference and User Services Association. http://www.ala.org/rusa/resources/guidelines/infoliteracy

Jensen, H. S. (2020). Digital archival literacy for (all) historians. Media History, 27(2), 251265. https://doi.org/10.1080/13688804.2020.1779047

National Archives and Records Administration. (2014). Strategy for digitizing archival materials for public access, 2015-2024. Retrieved February 2, 2021, from https://www.archives.gov/digitization/strategy.html

Office for Information Technology Policy's Digital Literacy Task Force. (2013). Digital literacy, libraries, and public policy. American Library Association. https://www.atalm.org/sites/default/files/Digital\%20Literacy,\%20Libraries,\%20and\%2 oPublic\%20Policy.pdf

The University of Chicago Press Editorial Staff. (2017). The Chicago manual of style (17th ed.). University of Chicago Press.

University of Delaware Library, Museums and Press. (n.d.). Joseph R. Biden, Jr., Senatorial Papers. Retrieved March 31, 2021, from https://library.udel.edu/special/joseph-rbiden-jr-senatorial-papers/

Weiner, S. A., Morris, S., \& Mykytiuk, L. J. (2015). Archival literacy competencies for undergraduate history majors. The American Archivist, 78(1), 154-180. https://doi.org/10.17723/0360-9081.78.1.154 